\title{
A defence of parental compromise concerning veganism
}

\section{Marcus William Hunt}

To cite this article: Marcus William Hunt (2021): A defence of parental compromise concerning veganism, Ethics and Education, DOI: 10.1080/17449642.2021.1927346

To link to this article: https://doi.org/10.1080/17449642.2021.1927346

曲 Published online: 13 May 2021.

Submit your article to this journal

Q View related articles $\sqsubset$

View Crossmark data \lceil 


\title{
A defence of parental compromise concerning veganism
}

\author{
Marcus William Hunt (D) \\ Department of Philosophy, Tulane University, New Orleans, United States
}

\begin{abstract}
Co-parents who differ in their ideal child rearing policies should compromise, argues Marcus William Hunt. Josh Milburn and Carlo Alvaro dispute this when it comes to veganism. Milburn argues that veganism is a matter of justice and that to compromise over justice is (typically) impermissible. I suggest that compromise over justice is often permissible, and that compromise over justice may be required by justice itself. Alvaro offers aesthetic, gustatory, and virtuebased arguments for ethical veganism, showing that veganism involves sensibilities and virtues, and argues that veganism involves a belief. Alvaro takes this to show that parental compromise is impermissible. I suggest that Alvaro's arguments are implausible and that the shaping of a child's sensibilities and virtues is an apt matter for parental compromise.
\end{abstract}

\section{KEYWORDS}

Animal ethics; compromise; family ethics; food ethics; veganism

\section{Introduction}

Using the case of a vegan and an omnivore who co-parent as an example, Marcus William Hunt argues that co-parents who differ in their preferred child rearing policies should compromise. This article defends Hunt's argument from objections made by Josh Milburn and Carlo Alvaro. Hunt's argument is that each co-parent has parental authority, and that for coparents to respect one another's authority they must give the same commands to the child, ones reflecting the ideals of both parents. Milburn and Alvaro do not raise general objections to Hunt's argument for parental compromise, but to its application to veganism. Milburn argues that to compromise over veganism for one's child is to compromise over a matter of justice, and that to compromise over matters of justice is (typically) impermissible. Alvaro argues that ethical veganism involves sensibilities, virtues, and beliefs, which, unlike actions, do not allow for intermediate compromise positions, or compromise positions that are responsive to the ideals of both parents. 


\section{Introducing Milburn's objection}

Hunt allows that some parental compromises are impermissible but does not give a theory of what makes them impermissible. As a placeholder, he uses the term 'extreme' commitments to designate the commitments that it is not permissible to compromise with, and offers reasons for thinking that extreme commitments are rare (Hunt 2019, 13-15).

Milburn's objection concerns this lacuna and is the hypothesis that extreme commitments are unjust commitments, compromising with which will be (typically) impermissible. Milburn advocates a rights-based approach to veganism on which killing and consuming an animal, and in most cases consuming animal products, is a rights-violation. This makes veganism a matter of justice. Many vegan co-parents surely agree. Milburn says that 'Any compromise on justice will be a tragedy, to be undertaken only in the most regrettable of circumstances' (Milburn 2020,4). Milburn is clear that his claim is not that 'justice can never be compromised upon, but that a compromise on justice is a tragedy' (Milburn 2020, 10-11 original italics). Milburn's position on the deontological question of when co-parents may compromise over veganism is left slightly vague (which seems entirely appropriate given the complexity of individual circumstances). Hence, I use the term 'typical' to describe Milburn's position on the deontological question.

\section{Criticisms of Milburn's objection}

First, I agree that compromise on justice is a tragedy, but this has little to tell us about the deontological question. Tragic emotions such as fear, reluctance, dismay, distress, grief, etc., alert us in various ways to a loss of value, e.g., that a loss of value is threatened, that it has occurred, that it has occurred avoidably. Justice is a value. So, such emotions are appropriate when contemplating a compromise that concerns a loss of justice. Yet, this does not indicate whether a given compromise represents a net-loss of value, or a net-loss that it would be impermissible to agree to. For example, when politicians contemplated introducing a Covid-19 lockdown in the spring of 2020 one hopes that they felt reluctance and distress about the loss of value that such lockdowns would cause, and that in retrospect they feel that the lockdown was tragic. To hope this is consistent with believing that the lockdown did not represent a net-loss of value and that introducing the lockdown was deontologically required.

Second, it seems that there are many cases in which it is permissible to make a compromise in which justice is lost in a trade-off with other values. Classic examples include the early prison releases of the Northern Irish Good Friday Agreement and the amnesties of the South African Truth and Reconciliation Commission, in which justice was traded-off for peace. The things gained in these cases were great compared with the gain of one token of 'domestic 
peace,' yet so were the things lost great compared with the injustice of killing an animal.

Third, in many cases of compromise one ends up pursuing a policy which is not the same as the policy one would pursue if not engaged in collective action with people who have differing conceptions of justice, but which is equally just. Several accounts of how this can be are offered in the political philosophy literature. Daniel Weinstock argues that compromise is required because 'the failure to compromise fails to do justice' to the need 'to make the ends of other members of the group one's own' (Weinstock 2013, 543). Christian Rostbøll argues that compromise is required by 'respect for fellow citizens as co-rulers' (Rostbøll 2017, 628). Fabian Wendt argues that compromise is valuable because it helps ensure the non-subjugation of citizens and the public justifiability of laws (Wendt 2017, 10-11). Plausibly, each of these values are aspects of justice. If we fail to, say, respect fellow citizens as co-rulers, or if we are indifferent to whether laws are publicly justifiable to them, we are unjust to them. So, what justice requires of us is sensitive to the conceptions of justice held by others in our political community. Each of these accounts does draw the line somewhere, after which compromise in the political domain is impermissible. To draw argumentatively on this observation would be to cast eaters of eggs into the unhappy company of racial or religious supremacists (a consistently drawn but, I think, implausible conclusion), rather than the happy company of social democrats and classical liberals with whom we should compromise. Simon May presents the most influential case against principled compromise in the political domain, but note that for May pragmatic compromises are both necessary and permissible in the political domain (May 2005, 317).

These latter two criticisms readily translate from the political to the personal domain. If it is an injustice to feed one's child animal products, it may be an injustice that is worth inflicting for the sake of 'domestic peace.' If it is an injustice to feed one's child animal products as a single-parent or when coparenting with another vegan, it may not be an injustice when co-parenting with an omnivore insofar as one should have respect for their co-rulership of one's child.

I think that Milburn is wrong in his hypothesis about what makes compromise (typically) impermissible, injustice. Nevertheless, some vegan co-parents may have a conception of veganism on which compromise is impermissible. Every parent has a responsibility to decide for themselves where they draw the line. Yet, to sustain the uncompromising position, the vegan co-parent should have a conception of veganism on which feeding animal products to one's child is proportionately worse than seemingly permissible political compromises. This amounts to the vegan coparent having a conception of veganism on which feeding animal products to their child is proportionately worse than murderers being set free, racist death squads being granted amnesties, reproductive rights being restricted, human persons being aborted, etc. If these compromises are permissibly made - with all due 
sense of tragedy - then probably compromise over veganism for one's child is permissible even on many justice-based conceptions of veganism.

\section{Introducing Alvaro's objections}

Hunt notes that parental compromise may concern many aspects of how the child is to be raised, including the child's beliefs. Hunt suggests that beliefs are often difficult to compromise over for two reasons (Hunt 2019, 15-17). First, the possibility of compromise requires that there be possible compromise positions. Yet, beliefs are the type of thing that often do not make for many or any possible compromise positions. Imagine a Christian and a Muslim who are co-parenting. Raising their child to hold both beliefs is not a possible compromise position, to the degree that holding contradictory beliefs is impossible. Second, possible compromise positions involving beliefs are often not responsive to the reasons of either co-parent. The Christian co-parent might desire that their child believe in Christianity for the reason that this is necessary for their child's salvation, and the Muslim co-parent might desire that their child believe in Islam for the same reason. Raising the child as a mere theist, or with unusual syncretic beliefs, are possible compromise positions, but ones that are not responsive to the reasons of either parent. Hunt supposes that, luckily, ethical vegans and omnivores are primarily interested in their child's actions rather than their beliefs. With respect to an action like eating a diet, innumerable compromise positions are available, many of which are responsive to the reasons of both co-parents (for the omnivore, things like nutrition, social ease, tradition, and for the vegan things like minimizing animal suffering).

As I read him, Alvaro makes two objections to parental compromise over veganism, concluding that 'ethical vegan parents should accept zero parental compromise over veganism' (Alvaro 2020b, 20). The first objection is that the moral reasons of ethical veganism go beyond the sort of consequentialist moral reasons that Hunt imagines. Alvaro provides an aesthetic argument, a gustatory argument, and two virtue arguments for ethical veganism, providing 'a richer understanding of the ethical vegan's commitment to veganism' (Alvaro 2020b, 18). Since veganism involves sensibilities and virtues it may not readily allow for possible compromise positions, or it may involve moral reasons to which possible compromise positions are not responsive. Alvaro's second objection is that ethical veganism does involve beliefs, meaning that there is not a wide spectrum of compromise positions available. These arguments are summed up in Alvaro's claim that 'veganism is in many important respects like a religion'(Alvaro 2020b, 3).

\section{Alvaro's aesthetic, gustatory, and virtue arguments}

Alvaro's arguments for ethical veganism are implausible, and even if granted they do not advance Alvaro's first objection. Note that with these arguments 
Alvaro is attempting to give an affirmative answer to the question 'If we discovered that animals do not suffer at all, would there be other arguments against animal exploitation?' (Alvaro 2020a, 29), so the arguments do not appeal to animal suffering itself.

\section{The aesthetic argument}

"(1) We ought to eliminate as far as we can (and we ought to avoid promoting) those practices that produce unnecessarily repugnant sights, sounds, and odors.

(2) Rearing animals for food produces unnecessarily repugnant sights, sounds and odors.

(3) Consequently, we ought to eliminate (and not promote) intensive animal farming." (Alvaro 2020b, 10)

Explaining (1), Alvaro appeals to human flourishing; 'a life that contains a lesser amount of unpleasant sights sounds and odors is more desirable and more conducive to flourishing than a life that features such unaesthetic value.' (Alvaro 2020b, 11). Explaining (2), Alvaro says that 'blood, bodily fluids, bad odor ... acoustic roughness ... are aspects characteristic of animal rearing and meat production' (Alvaro 2020b, 10) that are repugnant.

\section{Criticisms of the aesthetic argument}

My criticism of (1) is that it conflates potential loci of value - the overall aesthetic value of the world or a locality, and the overall aesthetic value of a life. Granting that animal farming reduces the overall aesthetic value of the world or a locality, this does not mean that animal farming reduces the overall aesthetic value of a life. The consumer of animal products does not usually experience the repugnant things involved in their production.

Alvaro might suggest that a life has a lower aesthetic value if it depends on the production of unnecessary repugnant things, even if the liver of that life never experiences them. It seems plausible that someone who lives off factory farmed meat imports a kind of non-sensory ugliness into their life. Perhaps this is because of the unnecessary repugnant processes of factory farming. In response, note that most dyeing processes for textiles involve repugnant odors (Kant 2012) and that dyed textiles seem no more necessary than meat. It is implausible that a life has a lower aesthetic value because the clothes enjoyed depend on repugnant odors. This suggests that it is something other than the unaesthetic nature of animal farming that lowers the aesthetic value of the life that depends on factory farmed meat.

I offer three criticisms of (2). First, not all forms of animal farming produce repugnant things. Coastal foraging for shellfish does not produce repugnant things. Indeed, coastal foraging is a popular form of recreation. Since his 
aesthetic argument is an argument for veganism it seems that it should identify an aesthetic problem that applies to animal farming in general.

Second, the bar for what makes repugnant things 'necessary' is lower than Alvaro imagines. Alvaro notes that processes 'such as making cars or cleaning septic tanks, disposing of garbage, surgical procedures, are not easily avoidable because are necessary aspects of our lives' (Alvaro 2020b, 11). The things mentioned are necessary in the sense that they have a high prudential value: we would be considerably worse off without them. Yet even minor prudential value can make necessary the production of repugnant things. Some read paper books in preference to e-books as they strain the eyes less, or to enhance the reading experience, or from habit. Pulp mills produce a vile sulphurous odor that can be smelled from many miles away (Mirabelli and Wing 2006). Yet, reading paper books seems permissible. So, the bar that makes the production of repugnant things necessary is low. So, reasons of taste, tradition, etc., make necessary the repugnant things of animal farming.

Third, Alvaro overlooks the possibility that the repugnant things of animal farming are not produced unnecessarily because these things unavoidably accompany the embodiment of higher aesthetic values. For instance, sexual intercourse between human beings usually produces sights, sounds, and odors that would be repugnant to any observer. The production of these things is often not unnecessary because (among other things) sexual intercourse between human beings can have a higher non-sensory aesthetic value. Animal farming may also embody higher aesthetic values. The idea of the 'Great Chain of Being' is that to manifest his goodness God creates a gradation of beings, the higher providentially guiding and being served by the lower. On this view, animal farming is one way in which we participate in the divine order. In less overtly theological terminology, such as 'we were made to eat animals,' the aesthetics of the Great Chain of Being live on for many people. Such an idea is hard to refute without engaging thorny questions in the philosophies of religion and teleology. More prosaically, some animal farming helps maintain landscapes of aesthetic value, which must be balanced against the repugnant sights, sounds, and odors, produced. England's pastoral countryside, the green and pleasant land, would be hard to maintain absent animal farming.

\section{The gustatory argument}

“(1) Meat is not inherently flavorful, but rather unappetizing.

(2) Whatever is inherently unappetizing should not be consumed.

(3) Therefore, meat should not be consumed." (Alvaro 2020b, 17) 
Concerning (1) Alvaro explains that 'meat is foul when raw and requires certain steps necessary to render it edible ... Meat is always aged, marinated, seasoned, and cooked .... meat is not consumed because it is good in itself. It is rendered good by masking and modifying its original flavour with the use of potent spices' (Alvaro 2020b, 15-17). Concerning (2) Alvaro argues that cooking meat 'constitutes an act of self-deception. Since one should avoid deceiving oneself, it follows that one should avoid eating meat' (Alvaro 2020b, 17).

\section{Criticisms of the gustatory argument}

An objection to (1) is that not all animal products are unappetizing in an uncooked state, cow's milk being an example. I offer three criticisms of (2).

First, (2) is an implausible principle on its face. Granting that meat is inherently unappetizing and that eating meat is wrong, it is not intuitive that the latter is true because the former is true. It also yields the wrong intuitive extension - it implies that consuming mud or mucus is morally impermissible when consuming these things seems morally permissible.

Second, Alvaro's claim that cooking meat is self-deceptive is only an objection to eating cooked meat. Eating uncooked meat would not count as selfdeceptive. So, Alvaro does not provide a reason for not consuming the inherently unappetizing as such, or meat as such. Naturally, even ardent carnivores have their reasons for not eating uncooked tripe, but these are reasons of prudence and taste rather than moral reasons. Avoiding self-deception may also rule out some plant foods. Alvaro may be happy to have 'chickenless nuggets' ruled out, but perhaps not Synsepalum dulcificum, the 'miracle berry' that makes sour things taste sweet.

Third, Alvaro's claim that cooking meat is self-deceptive relies on an implausible metaphysics of cooking. Roughly, self-deception involves leading oneself to believe (or, in this case, sense) to be true something that is not true. So, for cooking meat to involve self-deception it must be the case that cooked meat is in fact unappetizing and that we lead ourselves to sense that it is appetizing. Granting that uncooked meat is unappetizing, Alvaro overlooks the possibility that cooking meat changes meat from being unappetizing to being appetizing. Here are some reasons for favoring this possibility.

(i) Alvaro says that 'is not the taste of meat itself that meat eaters like, but rather the taste of the seasoning, spices, and flavors created by the cooking process' (Alvaro 2020b, 17). Yet, just as people tend not to eat uncooked meat, they also tend not to eat handfuls of herbs and spices. By themselves, neither are very appetizing. This suggests that here two things unappetizing alone become appetizing together, rather than the appetizing herbs and spices 'masking' the unappetizing meat. The appetizingness of the whole is greater than the sum of the appetizingness of the parts.

(ii) Alvaro describes uncooked meat as 'foul' - as disgusting. The disgusting is a property to which human beings are highly sensitive, and the action- 
tendencies of disgust are typically powerful (Rozin, Haidt, and McCauley 2008). This means that it is not plausible that the disgusting would go undetected, or be tolerated, by the addition of things that are not disgusting.

(iii) Cooking changes many properties of meat such as its color, moistness, texture, and taste. Plausibly, appetizingness is property that depends on these other properties - changes in texture and the like give rise to and destroy such a property. So, it is implausible to think that unappetizingness always persists despite changes in these properties - that no matter its changed texture, etc., meat persists in being unappetizing.

Alvaro might emphasize that it is only the inherently unappetizing that should not be consumed, as the premises state. Yet, Alvaro does not clarify this term. One thought is that the inherent properties of a thing are those properties which help constitute its existence. Yet, this gives the absurd result that a thing lacks one of the constitutive properties of meat, or is disqualified from being meat, if it is appetizing. Rather, an apple may be appetizing (when ripe) or unappetizing (when unripe, when rotten) and a piece of meat may be appetizing (when cooked) or unappetizing (when uncooked, when overcooked), but neither is inherently appetizing or unappetizing.

\section{The first virtue argument - non-violence}

"(1) Non-violence is a virtue in and of itself.

(2) Unnecessary violence ought to be avoided or eliminated.

(3) Intensive animal agriculture produces unnecessary - yet avoidable - violence.

(4) Therefore, intensive animal agriculture ought to be avoided or eliminated." (Alvaro 2020b, 13)

To explain the value being invoked by this argument Alvaro says:

"It is not (necessarily) our understanding that animals have the capacity for suffering that makes us cringe at the idea of killing and preparing an animal for consumption. It is the overt violence of using instruments such as knives, hammers, nail guns, and more to cut, pierce, smash, tear." (Alvaro 2020a, 36)

\section{Criticisms of the non-violence argument}

Regarding (1), the idea of non-violence as a virtue in and of itself is questionable. To ape Aristotle; one ought to be violent when the wise man would be violent, as he would be violent, for the reasons he would be violent. The wise man is sometimes violent. For example, a parent ought to be violent to defend their child from an attacker. So, non-violence is not a virtue 'in and of itself' any more than violence is. 
Regarding (3), I suggest that the bar for what makes violence 'necessary' is lower than Alvaro thinks. The sport of boxing involves violence (limited and ritualized, but very real). Boxing is engaged in for the sake of things like recreation or glory. Many agree that boxing is morally permissible. So, plausibly things like recreation or glory make the violence of boxing necessary. One can also be violent to plants (among other things, they are the sorts of beings that have changeable levels of well-being). If someone hacks down trees, tramples on saplings, and pours poison on seedbeds for no reason, this seems violent and something that should be avoided or eliminated. In Manichaeism the highest caste were forbidden from destroying plants (Rudolph 1987, 340), in Jainism the principle of Ahimsa ('non-violence') extends to not wantonly destroying plants (Dundas 2002, 27, 95, 106-7), and the Hindu Laws of Manu prescribe expiations for wantonly destroying plants (Manusmriti with the Commentary of Medhatithi 2018 , v. 11.144). Yet, most agree that violence towards plants is made necessary by minor considerations, such as making a path more traversable. By analogy then, the violence of animal agriculture is made necessary by minor considerations such as taste.

Alvaro might respond that the violence inflicted by animal farming is much worse than the violence that boxers do to each other or the violence that can be done to plants. I see no reason to think this if we internalize Alvaro's stipulation that the argument concerns violence as such rather than the pain caused by violence. Plausibly, what makes the violence inflicted on animals seem much worse is that we naturally perceive the piercing, smashing and tearing of flesh as causing pain.

\section{The second virtue argument - moderation}

Alvaro claims that 'ethical veganism should be the embodiment of the virtue of moderation (Temperance) ... moderation entails that a person avoids animalbased food' (Alvaro 2020b, 19). Elsewhere, Alvaro explains with approbation Aristotle's account of moderation (Alvaro 2017, 771). For Aristotle, 'Moderation and licentiousness are concerned with ... the pleasures of touch and taste' (Aristotle 2011, 1118a 24-26). So, the moderate person is one whose longing for the pleasures of touch and taste is neither excessive nor deficient. Further, Aristotle connects moderation to 'health or good conditioning' (Aristotle 2011, 1119a 15): even weak longing for a thing very destructive of health is immoderate. So, for moderation to entail veganism it must be that eating animal products is indicative of an excessive longing for the pleasures of touch and taste or that eating animal products is bad for health.

\section{Criticism of the moderation argument}

It does not seem that a diet containing some animal products is indicative of an excessive longing for the pleasures of touch and taste. The plant-based carrot 
cake and the typical carrot cake can both be the object of excessive longing, and both yield equally rich pleasures of touch and taste.

Alvaro might suggest here that any longing for animal products is immoderate not because animal products are especially rich in the pleasures of touch and taste but because to long for them is to prioritize the pleasures of touch and taste over other goods, such as an animal's well-being. By analogy, if someone longs for a token cotton shirt despite knowing that it was produced by forced labor in Uzbekistan then they are immoderate, even though longing for cotton shirts is not generally immoderate. In response, note that longing for animal products will only be immoderate if some other argument against animal farming is successful. The argument that moderation entails veganism depends on there already being some other successful argument for veganism; it is a supplemental consideration for those already convinced of the case for veganism. A vegan co-parent may indeed believe that they have some such argument in hand. Granting this, in the context of parental compromise to feed a child meat is not to immoderately prioritize the lowly good of the pleasure of touch and taste over the higher good of an animal's well-being, since the child is fed meat to (also) gain the good of showing respect for the parental authority of one's co-parent.

With respect to health, the claim required to show that only vegan diets are moderate is that any animal food in any quantity is bad for health. Such a claim is not supported by the current nutritional science literature. I limit myself to three points.

(i) Alvaro cites studies showing associations between meat intake and allcause mortality, fish intake and breast cancer, and egg intake with cardiovascular disease. Each of these associations are contested by other studies (Johnston et al. 2019; Zhihui et al. 2016; Drouin-Chartier et al. 2020). The issue of whether animal foods have bad health effects, in the quantities typically consumed in the developed world, is an object of lively debate among nutritional scientists (Leroy and Barnard 2020). This expert disagreement provides evidence that we cannot be sure that animal products have bad health effects, especially not in any quantity.

(ii) Vegan diets have been associated with other types of bad health. In one study $11.67 \%$ of births to vegan mothers were small for gestational age, versus $1.79 \%$ of births to omnivore mothers (Avnon et al. 2020). Vegan diets have been associated with higher risk of bone fracture (Tong et al. 2020) and dental erosion (Smits, Listl, and Jevdjevic 2020). Vegan diets have been associated with lower intakes of some micronutrients; in one recent study this was true of vitamin B12, vitamin D, calcium, iodine, and selenium (Fallon and Dillon 2020). So, granting that animal foods have some bad health effects, there are nevertheless tradeoffs to be made between different types of bad health. People can make these trade-offs in a variety of ways without being immoderate. Alvaro may claim that the associations I cite are contested elsewhere. If this is true, it only underscores 
that we are not in an epistemic position to say that moderation uniquely recommends veganism on health grounds.

(iii) Moderation is plausibly a concept that picks out things sufficiently conducive to health rather than things maximally conducive to health. Suppose that someone who eats a Standard American Diet would gain 10 years of healthy life expectancy by switching to a Mediterranean diet, or 10 years and 1 month of healthy life expectancy by switching to a vegan diet. It would be immoderate to remain on the Standard American Diet. Yet it is implausible to say that they remain immoderate after switching to the Mediterranean diet, even though it is not the healthiest diet possible. To assert that they remain immoderate would indicate a failure to give to give the pleasures of touch and taste their due, an insensible immoderation.

\section{Sensibilities, virtues, and compromise}

Alvaro's arguments do not provide moral reason for ethical veganism. Yet, many ethical vegans do in fact have certain aesthetic and gustatory sensibilities; they find slaughter repugnant and animal products unappetizing. An ethical vegan co-parent may desire to cultivate in their child these sensibilities. This desire has ethical significance for their co-parent even if the arguments for having these sensibilities are not compelling, as with many religious sensibilities. If it is the case that sensibilities and virtues make compromise positions unavailable or unresponsive to the reasons of parents, then co-vegan parents might be justified in not compromising. However, this is not the case.

Concerning possible compromise positions, sensibilities and virtues are exactly the sorts of things that allow for compromise positions. Consider the aesthetic and gustatory sensibility of a typical vegetarian - revolted by meat but salivating over the perfectly poached egg. This is a sensibility intermediate between that of a vegan and that of an omnivore. Virtues also allow for possible compromise positions - with indefinite gradations one can be more or less moderate or slothful or patient. Concerning reasons-responsiveness, the case of a child with the sensibility of a typical vegetarian is one in both co-parents see that their child's sensibility reflects their own, though only partly. The same is true of virtues. Raising the child as a vegetarian, or pescatarian, or flexitarian, responds to, and imperfectly embodies, the vegan co-parent's conception of moderation and also the virtues that the omnivore co-parent sees important, say, easygoingness and respect for tradition. So, the sensibilities and virtues involved in ethical veganism do not make it the case that compromise positions are unavailable or that those positions are unresponsive to the reasons of both co-parents.

\section{Ethical veganism and belief}

Alvaro argues that ethical veganism involves belief, like religion: 


\begin{abstract}
"Abstinence from animal products is the core doctrine of veganism. A vegan who intentionally eats animal products even once a year is by definition not a vegan. This is comparable to the specific, narrow, and exclusionary claims of Christianity ... for an ethical vegan to incorporate animal products in his or her diet ... would be tantamount to rejecting the very core moral belief of veganism." (Alvaro 2020b, 4-6)
\end{abstract}

Here we have the claim that holding certain beliefs is a necessary condition on being an ethical vegan, and the claim that intentionally eating animal products is tantamount to rejecting that belief. As a reason for rejecting this first claim consider Vera:

Vera has never eaten animal products. She has a strong behavioral disposition against doing so. She is disgusted by the idea. She finds animal agriculture unaesthetic. Vera is a Pyrrhonian sceptic who does not hold any beliefs about the ethics of veganism.

Vera counts as a vegan given what she eats. Vera counts as an ethical vegan given her behavioral disposition and her aesthetic and gustatory sensibilities. This is because her behavioral disposition and sensibilities are made sense of by certain moral principles, even though Vera does not hold beliefs about these moral principles. Equally, one can be a practitioner of other ethical practices without holding beliefs about the moral principles that make sense of them one can be a good employer without having beliefs about business ethics, one can be a good friend without having beliefs about the ethics of friendship. If these judgements about Vera are right, then holding a particular belief is not a necessary condition on being an ethical vegan. By contrast, to check Alvaro's analogy, if we imagine someone who does not believe in Christianity but nevertheless has certain Christian sensibilities and engages in Christian practices, it is extremely doubtful that they count as a Christian.

Next, consider Alvaro's claim that intentionally eating animal products is tantamount to rejecting the beliefs of ethical veganism. If someone believes that they ought not to X but nevertheless Xs then they have, if not rejected that belief, introduced a kind of incoherence between their theoretical and their practical reason. This is bad. I do not think that ethical vegans who compromise with omnivore co-parents and so feed their child animal products involve themselves in such incoherence or reject the belief in question. Alvaro does not say precisely what the belief central to ethical veganism is. Many plausible proposals are not in tension with feeding one's child animal products. The belief might be:

(1) There is strong moral reason to abstain from animal products.

(2) Usually or always, it is obligatory to abstain from animal products.

(3) Abstaining from animal products is good, not doing so is bad.

(4) (1-3), and there is some moral reason to ensure that others abstain from animal products. 
Someone can believe things like (1-4) and coherently believe that they ought to feed their child animal products. For feeding one's child animal products to be tantamount to rejecting the belief central to ethical veganism, that belief must be more deontologically prohibitive, involving or entailing (5):

(5) It is always obligatory to ensure that my child abstains from animal products.

It is implausible that the belief central to ethical veganism involves or entails (5), since this would yield the result that many people who eat vegan diets, and have all the sensibilities and virtues Alvaro describes, yet only believe things like (1-4), are not ethical vegans. So, even if veganism does involve a belief, plausible candidates for this belief are not in tension with the practice of feeding one's child animal products. Though not fully imparting an ethical practice such as veganism to one's child may be tragic, it is not wrong.

\section{Disclosure of potential conflicts of interest}

No potential conflict of interest was reported by the author(s).

\section{ORCID}

Marcus William Hunt (D) http://orcid.org/0000-0001-6858-1903

\section{References}

Alvaro, C. 2017. "Ethical Veganism, Virtue, and Greatness of the Soul." Journal of Agricultural \& Environmental Ethics 30 (6): 765-781. doi:10.1007/s10806-017-9698-z.

Alvaro, C. 2020a. Raw Veganism: The Philosophy of the Human Diet. New York: Routledge.

Alvaro, C. 2020b. "Vegan Parents and Children: Zero Parental Compromise" Ethics and Education Online: 1-23. doi: 10.1080/17449642.2020.1822610.

Aristotle. 2011. "Nicomachean Ethics." In Translated by Robert Bartlett and Susan Collins. Chicago: University of Chicago Press.

Avnon, T., E. P. Dubinsky, I. Lavie, T. B.-M. Bashi, R. Anbar, and Y. Yogev. 2020. "The Impact of a Vegan Diet on Pregnancy Outcomes" Journal of Perinatology Online: 1-5. doi: 10.1038/ s41372-020-00804-x.

Drouin-Chartier, J.-P., S. Chen, L. Yanping, A. L. Schwab, M. J. Stampfer, F. M. Sacks, B. Rosner, W. C. Willett, F. B. Hu, and S. N. Bhupathiraju. 2020. "Egg Consumption and Risk of Cardiovascular Disease: Three Large Prospective US Cohort Studies, Systematic Review, and Updated Meta-Analysis" British Medical Journal Online: m513. doi: 10.1136/ bmj.m513.

Dundas, P. 2002. The Jains. 2nd ed. London: Routledge.

Fallon, N., and S. A. Dillon. 2020. "Low Intakes of lodine and Selenium Amongst Vegan and Vegetarian Women Highlight a Potential Nutritional Vulernability." Frontiers in Nutrition 7 (72): 1-6. doi:10.3389/fnut.2020.00072. 
Hunt, M. W. 2019. "Parental Compromise" Critical Review of International Social and Political Philosophy Online: 1-21. doi: 10.1080/13698230.2019.1644582.

Johnston, B. C., D. Zeraatkar, M. A. Han, R. W. M. Vernooij, C. Valli, R. E. Dib, C. Marshall, P. J. Stover, S. Fairweather-Tait, and W. Grzegorz. 2019. "Unprocessed Red Meat and Processed Meat Consumption: Dietary Guideline Recommendations from the Nutritional Recommendations (Nutrirecs) Consortium." Annals of Internal Medicine 171 (10): 756-767. doi:10.7326/M19-1621.

Kant, R. 2012. "Textile Dyeing Industry An Environmental Hazard." Natural Science 4 (1): 22-26. doi:10.4236/ns.2012.41004.

Leroy, F., and N. D. Barnard. 2020. "Children and Adults Should Avoid Consuming Animal Products to Reduce Risk for Chronic Disease: NO." American Journal of Clinical Nutrition 112 (4): 931-936. doi:10.1093/ajcn/nqaa236.

"Manusmriti with the Commentary of Medhatithi." 2018. "Wisdom Library." 2018. https:// www.wisdomlib.org/hinduism/book/manusmriti-with-the-commentary-of-medhatithi/d/ doc202034.html

May, S. C. 2005. "Principled Compromise and the Abortion Controversy." Philosophy \& Public Affairs 33 (4): 317-348. doi:10.1111/j.1088-4963.2005.00035.x.

Milburn, J. 2020. "Should Vegans Compromise?" Critical Review of International Social and Political Philosophy Online: 1-13. doi: 10.1080/13698230.2020.1737477.

Mirabelli, M., and S. Wing. 2006. "Proximity to Pulp and Paper Mills and Wheezing Symptoms among Adolescents in North Carolina." Environmental Research 102 (1): 96-100. doi:10.1016/j.envres.2005.12.004.

Rostbøll, C. F. 2017. "Democratic Respect and Compromise." Critical Review of International Social and Political Philosophy 20 (5): 619-635. doi:10.1080/13698230.2017.1328092.

Rozin, P., J. Haidt, and C. R. McCauley. 2008. "Disgust." In Handbook of Emotions, edited by M. Lewis, M. H.-J. Jeannette, and L. F. Barrett, 757-776. 3rd ed. New York: Guilford Press.

Rudolph, K. 1987. Gnosis: The Nature and History of Gnosticism. New York: HarperCollins.

Smits, K. P. J., S. Listl, and M. Jevdjevic. 2020. "Vegetarian Diet and Its Possible Influence on Dental Health: A Systematic Literature Review." Community Dentistry and Oral Epidemiology 48 (1): 7-13. doi:10.1111/cdoe.12498.

Tong, T. Y. N., P. N. Appleby, E. G. Miranda, G. K. Armstrong, A. K. Fensom, K. Papier, R. C. T. Aurora Perez-Cornago, and T. J. Key. 2020. "Vegetarian and Vegan Diets and Risks of Total and Site-Specific Fractures: Results from the Prospective EPIC-Oxford Study." BMC Medicine 18 (1): 1-15. doi:10.1186/s12916-020-01815-3.

Weinstock, D. 2013. "On the Possibility of Principled Moral Compromise." Critical Review of International Social and Political Philosophy 16 (4): 537-556. doi:10.1080/ 13698230.2013 .810392$.

Wendt, F. 2017. "Compromise and the Value of Widely Accepted Laws." In Compromise and Disagreement in Contemporary Political Theory, edited by C. Rostbøll and T. Scavenius, 50-62. London: Routledge.

Zhihui, W., Y. Weihua, W. Zupei, and H. Jinlin. 2016. "Fish Consumption and Risk of Breast Cancer: Meta-Analysis of 27 Observational Studies." Nutricion Hospitalaria 33 (3): 703-712. doi:10.20960/nh.282. 